\title{
RAPD based Genetic Diversity of Endangered Himalayan Gray Langur (Semnopithecus ajax) Populations of Pakistan
}

\author{
Riaz Aziz Minhas 1,*, Muhammad Nasim Khan', Muhammad Siddique Awan', \\ Basharat Ahmad ${ }^{1}$, Syda Shaista Bibi ${ }^{1}$, Mohsin Hanif ${ }^{1}$ and Afsar Mian ${ }^{2}$ \\ ${ }^{1}$ Department of Zoology, University of Azad Jammu and Kashmir, Muzaffarabad \\ ${ }^{2}$ Bioresource Research Centre, 34-Bazaar Road, Sector G-6/4, Islamabad
}

\begin{abstract}
A B S T R A C T
Gray langurs (Semnopithecus spp.) are leaf eating monkeys fragmentally distributed in northern hills of Khyber Pakhtunkhwa (KP) and Azad Jammu and Kashmir (AJK). It was believed that different fragmented populations of these monkeys might have experienced a genetic isolation or inbreeding. We assessed the level of genetic diversity and genetic isolation of different langur populations using Randomly Amplified Polymorphic DNA (RAPD) genetic markers. We collected 86 different samples (feces 64, hair 13, blood 5 , tissues 4) from 5 geographic langur populations of Pakistan and Azad Jammu and Kashmir (AJK) and succeeded in extraction of DNA from 23 samples, which were used for further genetic analysis. RAPD makers $(n=8)$ produced 245 bands ( $30.62 \pm 2.87$ Mean \pm SE / primer) of different molecular weights (126$3342 \mathrm{bp}$ ), of which, 96 were population specific. Polymorphism was $(37.71 \pm 5.29 \%$; mean \pm SE), with the highest in Muzaffarabad population (54.29\%), followed by Poonch (43.67\%) and Neelum (36.73\%). Values of Shannon's (I: $0.129-0.200)$ and Nei's genetic diversity (He: $0.082-0.117)$ indices were low. Total heterozygosity (Ht: $0.144 \pm 0.007$ ), genetic diversity within population (Hs: $0.096 \pm 0.005$ ), between populations (Dst: $0.018 \pm 0.003$ ), genetic differentiation constants among populations (Gst: $0.153 \pm 0.025$ ) and within populations (Rst: $0.847 \pm 0.025$ ) were calculated. Gene flow (Nm: $3.246 \pm 0.448$ ) and genetic similarity (97-98\%) between populations was high. UPGMA based dendrogram identified five distinct geographic groups, and Mantel tests $(R x y=-0.008, \mathrm{P}>0.05)$ suggested a non-significant relationship between genetic distance and geographic distance. Phist $\left(\Phi_{P T}\right)$ value suggested a significance difference in within population and between populations $\left({ }_{P T}=0.042 ; \mathrm{p}=0.006\right)$ variances, suggesting that within populations variation was higher $(96 \%)$ than variation between populations $(4 \%)$. Present study suggested a low level of genetic diversity; however, gene flow was higher suggesting low chances of inbreeding between gray langur populations of Pakistan and AJK.
\end{abstract}

\begin{tabular}{l} 
Article Information \\
Received 18 December 2017 \\
Revised 03 March 2018 \\
Accepted 11 April 2018 \\
Available online 31 August 2018 \\
Authors' Contribution \\
\hline RAM designed the study, collected \\
field data, extracted genome and wrote \\
the article. MH and SSB amplified \\
the primers. BA and MSA statistically \\
analyzed the data. MNK and AM \\
supervised the study and revised the \\
manuscript. \\
Key words \\
Genetic diversity, Himalayan gray \\
langur, RAPD, Pakistan.
\end{tabular}

\section{INTRODUCTION}

K ashmir gray langur or Himalayan gray langur (Semnopithecus ajax) is an endangered species of old-world monkey fragmentally distributed in different areas of northern Pakistan (Khyber Pukhtunkhwa (KP) and Azad Jammu and Kashmir (AJK)) (Roberts, 1997; Minhas et al., 2012). In AJK, these monkeys have been recorded in District Neelum, Muzaffarabad, Jhelum valley and Bagh (Ahmed et al., 1999; Minhas et al., 2012). In KP, they have been reported from different localities of district Mansehra and Kohistan (Roberts, 1997; Minhas et al., 2012). There are geographical and ecological reasons to believe that different populations of langur were isolated from one another, but the level of isolation was not known. Threatened species with isolated

\footnotetext{
Corresponding author: riazminhas79@yahoo.com 0030-9923/2018/0006-2059 \$ 9.00/0

Copyright 2018 Zoological Society of Pakistan
}

populations of few breeding individuals often have lower genetic diversity (Lacy, 1997). Knowledge of the extent of isolations existing between different populations and sizes of individual populations has a conservation value. Smaller isolated populations having higher chances of being genetically fixed through inbreeding and dwindle to extinction due to accumulation of unflavored alleles and genetic homogeneity (Lacy, 1997). Use of molecular genetic markers in assessment of the conservation status of a population/species is a new trend. Genetic variability in the population has a predictive value for the potentials of the species/population to cope with future environmental fluctuations and its continued survival under environmental odds (Frankham et al., 2002). Information of genetic variation within and among populations and applications of genetic principles are considered as crucial scientific tools for wildlife managers in making proper decisions for conserving populations (Bellemain, 2004).

The assessment of genetic diversity has been made easier with the development of molecular genetic markers. 


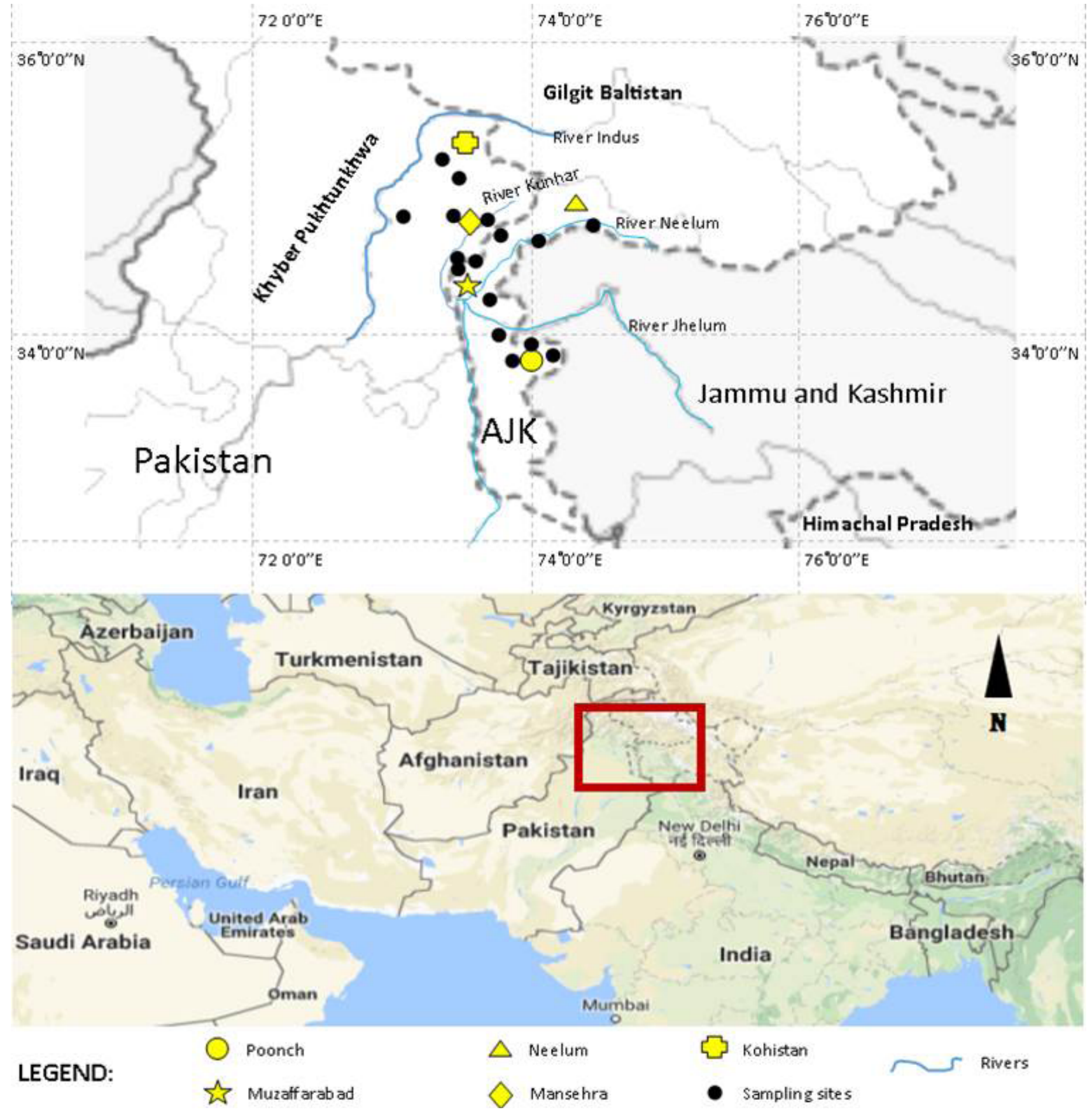

Fig. 1. Location map of gray langur populations with sampling localities in Pakistan.

Molecular genetic markers are heritable characters with multiple states ranging between one, two or multiple states (alleles) per character (locus). All genetic markers reflect variations in DNA sequences, usually with a trade-off between precision and convenience (Sunnucks, 2000). Several molecular markers have been used in genetic diversity studies, including, informative or co-dominant markers, e.g., microsatellite (SSRs) and restriction fragment length polymorphism (RFLP), and non-informative or dominant markers, such as, random amplified polymorphic DNA (RAPD) and amplified fragment length polymorphism (AFLP; Nassiry et al., 2009). RAPD markers are easily developed and analyze using PCR amplification techniques. During RAPD 
analysis the banding patterns of two closely related species/populations are more similar than the evolutionary unrelated species/populations (Miesfeld, 1999). RAPD technique has become popular for genetic comparison of organisms where relatively small-scale DNA sequences are compared using many genetic markers without cloning and sequencing of the genome of the species in question (Kumar and Gurusubramanian, 2011). These markers are used for genetic diversity analysis of different vertebrates due to limitation in cost, time and labour (Kumar and Gurusubramanian, 2011; Vasave et al., 2014; Shafi et al., 2016; Mudasir et al., 2016). These markers have also been used for genetic studies in different taxa of primates including langurs (Ding et al., 2000; Arif and Khan, 2009).

The study was based upon the hypothesis that different inbreeding populations of the gray langur distributed in Pakistan and Azad Jammu and Kashmir are isolated to different degrees from one another. Gray langur, being endangered in Pakistan/AJK, we planned to identify individual populations and characterize them using molecular genetic tools to work out the intra-specific variability using molecular genetic analysis. These research findings will have a value for the conservation biologists and managers in settling the present status of langurs in Pakistan and can be used in development of future langur population management strategy.

\section{MATERIALS AND METHODS}

\section{Sampling}

Based on information about langur population, available with literature and wildlife staff, a reconnaissance survey of potential gray langur areas was conducted in 2012-2013. A total of 86 samples (feces 64, hair 13, blood 5, tissues 4$)$ were collected from 5 localities viz. Palas valley, district Kohistan, KP (3452' $-35^{\circ} 16^{\prime}$ N, 72 $\left.2^{\circ} 52^{\prime}-73^{\circ} 35^{\prime} \mathrm{E}\right)$; Allai valley, District Battagram, KP (343' $-34^{\circ} 47^{\prime} \mathrm{N}$, $\left.72^{\circ} 54^{\prime}-73^{\circ} 15^{\prime} \mathrm{E}\right)$; Kaghan valley, District Mansehra, KP $\left(34^{\circ} 14^{\prime}-35^{\circ} 11^{\prime} \mathrm{N}, 72^{\circ} 49^{\prime}-74^{\circ} 08^{\prime} \mathrm{E}\right)$; Machiara National Park, AJK ( $\left.34^{\circ}-31^{\prime} \mathrm{N}, 73^{\circ}-37^{\prime} \mathrm{E}\right)$; Neelum valley, AJK $\left(34^{\circ} 28^{\prime}-34^{\circ} 48^{\prime} \mathrm{N}, 73^{\circ} 91^{\prime}-74^{\circ} 58^{\prime} \mathrm{E}\right)$; Jhelum valley, AJK

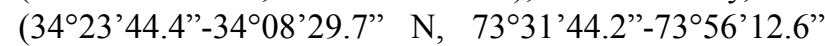
E); Las Danna, AJK (33.9212 $\left.{ }^{\circ} \mathrm{N}, 73.9550^{\circ} \mathrm{E}\right)$ and Haveli Kahuta, AJK $\left(33.8841^{\circ} \mathrm{N}, 74.1083^{\circ} \mathrm{E}\right)$ (Fig. 1).

For collection of fresh fecal material, langur troops were followed and about 20-50 gm of out layers of fecal samples were collected in sterilized polypropylene tubes containing 95\% ethanol following Nsubuga et al. (2004) and Zhang et al. (2006). Hair samples, collected from the roosting sites/resting rocks/bushes were removed with forceps and transferred to a clean paper envelope and packed separately in zipped polyethylene bags and stored at $4^{\circ} \mathrm{C}$ till DNA was extracted and analyzed. Tissues samples (skin, muscle, liver) were collected from the carcasses of leopard/human killed $(n=4)$ and were preserved in sterilized polyethylene bags polypropylene tubes filled with $95 \%$ ethanol or simply collected in sterile polyethylene bags. Dried muscle samples $(n=3)$ were also collected from preserved material, available locally, and stored in clean sterile paper envelopes, and stored at $-20^{\circ} \mathrm{C}$. Blood $(n=5)$ samples were collected from langurs freshly killed ( $\mathrm{n}=2$; within 24 hours) or maintained in illegal custody ( $\mathrm{n}=3$ ), using $10 \mathrm{ml}$ sterile syringes (BD, USA), transferred to $10 \mathrm{ml}$ potassium EDTA vacutainer tubes (BD, USA), labeled, and stored at $4^{\circ} \mathrm{C}$, in refrigerator in the laboratory.

\section{Ethics statement}

This study did not require approval by any ethics committee as all samples were collected through noninvasive methods without incision of live wild animals. However, for field samplings a permit was acquired by the Department of Wildlife vide letter Number. WL\&F/713/2015, dated November 16, 2015. The blood samples were collected with the help of a trained veterinarian through the sterile syringes from individuals illegally held by the locals.

\section{DNA extraction}

DNA was extracted from blood tissues by using method of Sambrook et al. (1989); however, for DNA extraction from fresh and dried tissues, some modifications were carried out. To modify this method, tissues were washed twice with $100 \%$ ethanol (by dipping for $15 \mathrm{~min}$ ) and distilled water (10 min) each and grinded using liquid nitrogen. To the powdered tissues, $750 \mu \mathrm{l}$ of Solution A (0.32 M Sucrose; $10 \mathrm{mM}$ Tris-pH 7.5; $5 \mathrm{mM} \mathrm{MgCl}_{2} ; 1 \%$ (v/v) Triton X-100) was added and incubated overnight at $37^{\circ} \mathrm{C}$. On the next day after centrifugation for $1 \mathrm{~min}$ at $13000 \mathrm{rpm}$, the supernatant was discarded and the nuclear pellet mixed with $500 \mu \mathrm{l}$ of Solution B (10 mM Tris-pH 7.5; $400 \mathrm{mM} \mathrm{NaCl}, 2 \mathrm{mM}$ EDTA - $\mathrm{pH}$ 8.0) along with $20 \mu \mathrm{l}$ of $20 \% \mathrm{SDS}$ and proteinase-K each. This mixture was incubated at $37^{\circ} \mathrm{C}$ for $24-36 \mathrm{~h}$. For rest of the steps, protocol of Sambrook et al. (1989) was followed. From hair, follicles of about one $\mathrm{cm}$ from the root were cut by sterile razor blade and washed with $95 \%$ ethanol and then distilled water. Subsequent steps were the same as described above for blood/tissues. The extracted DNA was dissolved in 50-70 $\mu$ l of TE buffer. Methods of Zhang et al. (2006) was adopted for extraction DNA from fecal samples. While extraction DNA from fecal materials, negative extraction controls were also processed following Liu et al. (2008). For confirmation of DNA presence, the 
extracted DNA was run on $1 \%$ agarose gel and visualized using gel documentation system (Vilber Lourmat Bio-PrintST4, France) for evaluation the quality, while quantity of

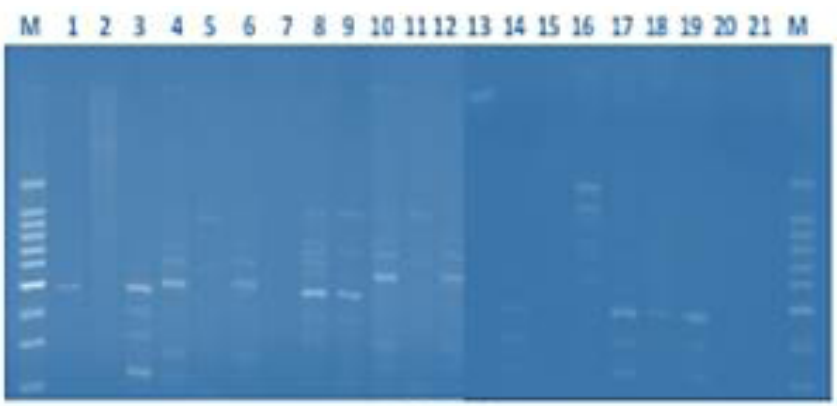

OPC -2

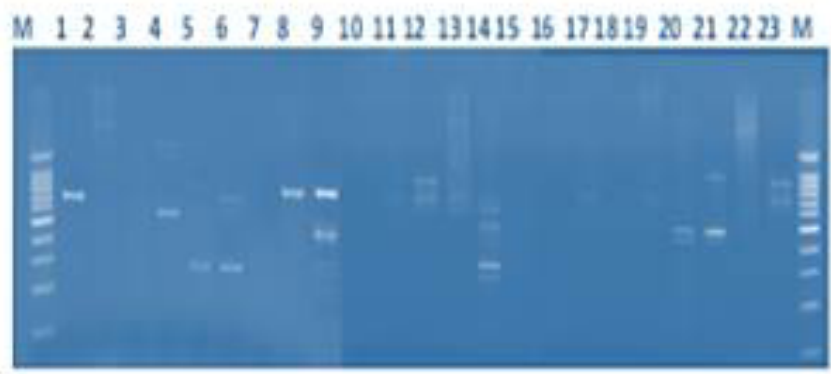

OPC -7

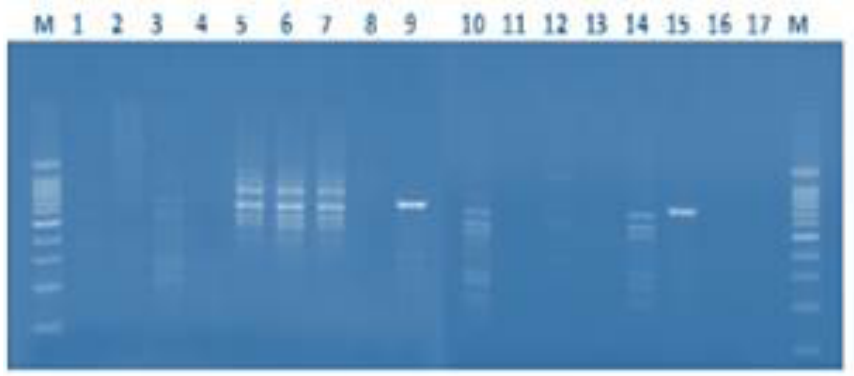

OPD-02

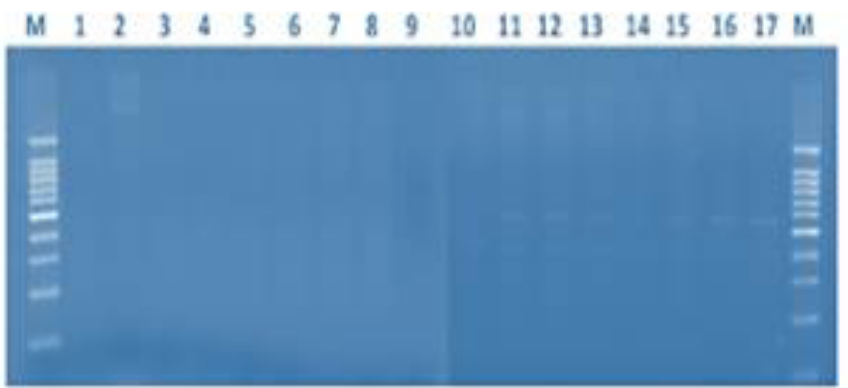

OPD-04
DNA was assessed using spectrophotometer (UV3000, Germany). DNA samples with 1.7-2.0 absorbance ratios were subjected to PCR amplification.

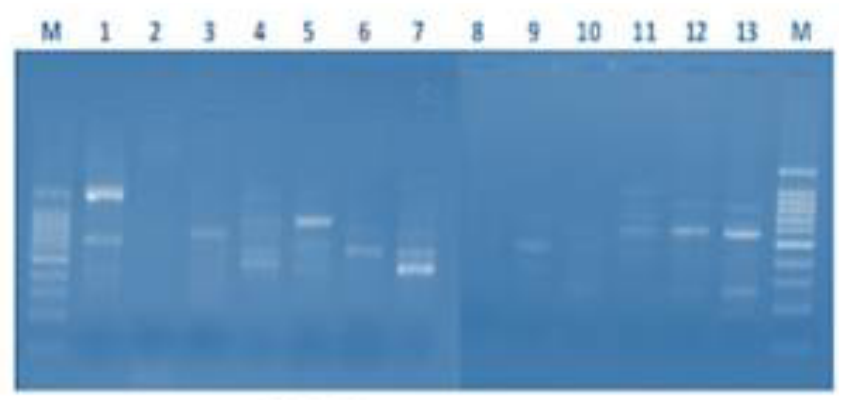

OPC-5

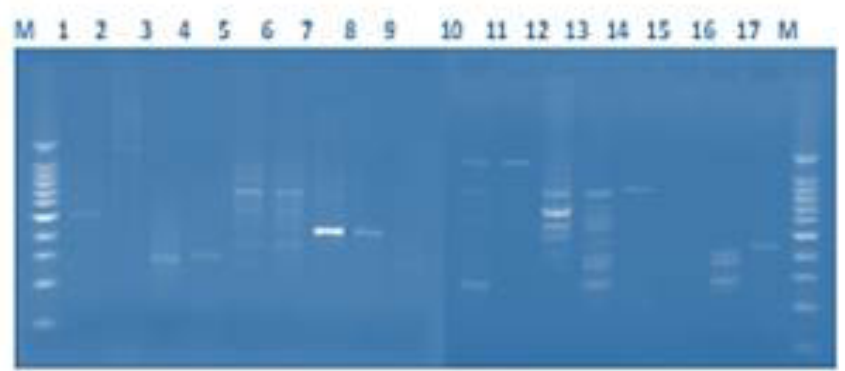

OPC -9

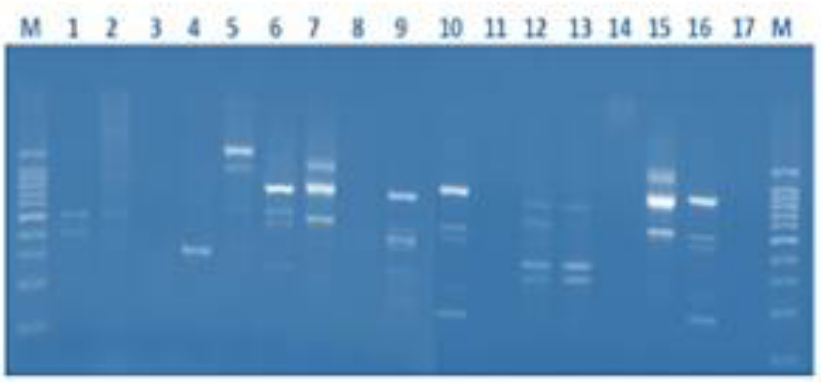

OPD-03

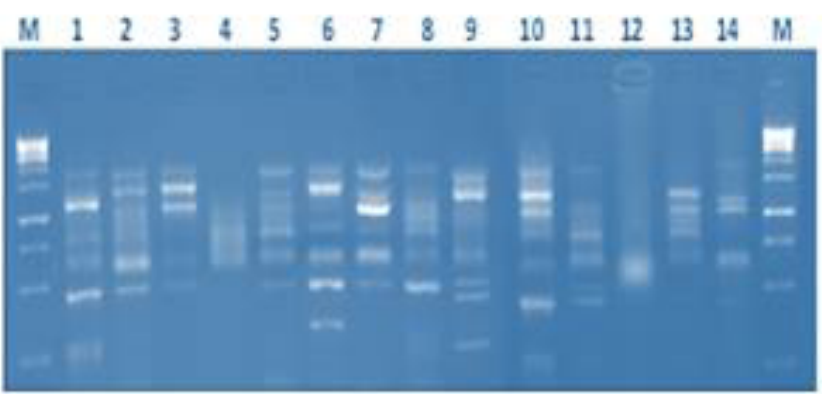

OPA-04

Fig. 2. Gel pictures (2\%) of PCR products of RAPD markers (1-8) for gray langur populations of Pakistan (M=100bp/1kb Ladder). 
PCR optimization and amplification

Eight primers were used for amplification of 23 DNA samples of gray langur (Table I) and these primers were randomly selected from published papers (Ding et al., 2000; Shafi et al., 2016). The PCR reaction consisted of initial denaturation at $94^{\circ} \mathrm{C}$ for 5 min followed by 39 cycles of $1 \mathrm{~min}$ denaturation at $94^{\circ} \mathrm{C}$, annealing at different temperatures (specific to each primer) for $30 \mathrm{sec}$ to $1 \mathrm{~min}$ and extension of strand at $72^{\circ} \mathrm{C}$ for $1 \mathrm{~min}$. To ensure the completion of extension process, a further extension at $72^{\circ} \mathrm{C}$ was carried out for $10 \mathrm{~min}$. For optimization of the annealing temperatures of primers were adjusted by lowering the 2-5 degrees from the calculated melting temperatures by using the equation $\mathrm{T}_{\mathrm{m}}=4(\mathrm{G}+\mathrm{C})+$ $2(\mathrm{~A}+\mathrm{T})$, where ' $\mathrm{G}$ ', ' $\mathrm{C}$ ', ' $\mathrm{A}$ ', and ' $\mathrm{T}$ ' represent the number of respective nucleotides in the primer. The amplification success and quality of the PCR products of RAPD was assessed by performing 2\% agarose gel electrophoresis. Gel documentation system was used for visualization of the quality of the amplified products and picturizing of the band patterns. The gel photographs of the amplified products were used for further analysis by scoring the absence or presence of different bands (Fig. 2).

Table I.- RAPD markers used in genotyping of Himalayan gray langurs (after Ding et al., 2000).

\begin{tabular}{lcc}
\hline Primer & Sequence & G+C content (\%) \\
\hline OPC-2 & 5'-GTGAGGCGTC-3' & 70 \\
OPC-5 & 5'-GATGACCGCC-3' & 70 \\
OPC-7 & 5'-GTCCCGACGA-3' & 70 \\
OPC-9 & 5'-CTCACCGTCC-3' & 70 \\
OPD-02 & 5'-GGACCCAACC-3' & 70 \\
OPD-03 & 5'-GTCGCCGTCA-3' & 70 \\
OPD-04 & 5'-TCTGGTGAGG-3' & 60 \\
OPA-04 & 5'-AATCGGGCTG-3' & 60 \\
\hline
\end{tabular}

\section{Discriminatory powers of markers}

To assess the discriminatory powers of markers, each RAPD marker was analyzed for different informative indices, including polymorphism information content (PIC), resolving power (RP), marker index (MI), and effective multiplex ratio (EMR), calculated in MS Excel 2016 using the following relationships (Mandal et al., 2016; Pecina-Quintero et al., 2012; Kayis et al., 2010): $\mathrm{PIC}=2 \mathrm{f}_{\mathrm{i}}\left(1-\mathrm{f}_{\mathrm{i}}\right)$; where, $f_{i}$ is the frequency of marker band present and $1-f_{i}$ is the frequency of marker absent bands (Roldàn-Ruiz et al., 2000) $\mathrm{MI}=\mathrm{PIC} \times$ number of polymorphic loci, or, $\mathrm{MI}=\mathrm{PIC} \times \mathrm{EMR}$, where, $\mathrm{EMR}=$ $\mathrm{n} \beta$ is the effective multiplex ratio, measured as the product of the total number of loci per fragments per primer (n) and the fraction of polymorphic loci fragments $(\beta)$ (Pecina-Quintero et al., 2012). RP $=\Sigma \mathrm{Ib}$, were "Ib" is the informativeness of band, calculated as $\mathrm{Ib}=1-[2 \times(0.5-$ p)], being " $p$ " the proportion of each genotype containing the band. The diversity index (DI), indicating the genetic diversity or expected heterozygosity at the locus, $=1-1 / \mathrm{L}$ $\Sigma \mathrm{Pi}$, where, $\mathrm{Pi}$ is the allele frequency in (each individual allele is considered a unique fragment amplification) and $\mathrm{L}$ is the number of loci (Mandal et al., 2016).

\section{Genetic data analysis}

Scoring of bands: Beside visual observations, the Software (GelAnalyzer-2010a) was used to record presence or absence of bands (Arruda et al., 2012; Abeykoon et al., 2015). Binary matrix of each genotype was recognized as presence " 1 " and absence " 0 " of bands. The percentage of polymorphic bands and bivariate (1-0) data matrix for each primer was analyzed using the software (MS Excel 2016, GenAlEx-6.5; Popgene-1.31). Using presence or absence data, the calculations of genetic distances (Fitzpatrick, 2009) and the degrees of similarities or dissimilarities of RAPD fragments between individuals and populations were carried out using Popgene and GenAlEx-6.5 (Peakall and Smouse, 2012).

Genetic diversity, genetic differentiation and gene flow

For calculation of different genetic diversity attributes including allele frequencies, total numbers of observed $(\mathrm{Na})$ and effective alleles $(\mathrm{Ne})$, genetic diversities, Shannon' Information Index (I), Nei's Gene Diversity Index $(\mathrm{He})$ or expected heterozygosity, total heterozygosity $(\mathrm{Ht})$, genetic diversity within $(\mathrm{Hs})$ and between (Dst) populations, genetic differentiation within (Rst) and between (Gst) populations and gene flow $\left(\mathrm{N}_{\mathrm{m}}\right)$ were calculated and analyzed by using the Popgene (1.32), GenAlEx (6.5) and MS Excel (2016) software programs (Yeh et al., 1999; Gaudeul et al., 2004).

\section{Genetic similarity and genetic distance}

Nei's genetic similarities and distances were calculated based on pairwise population matrix of different populations using GenAlEx (6.5). Cluster analysis was carried out by constructing dendrograms in Popgene (1.32) program using un-weighed pair group mathematical averages (UPGMA). These dendrograms were based on Nei's genetic distances/similarities data for different populations as well as different genotypes (Nei, 1972, 1978). Clustering of different genotypes from gray langur populations was performed using Euclidean similarity index based on Paired group cluster analysis of binary data (present/absent) produced by different markers in Past (3.16) software (Hammer et al., 2001). 

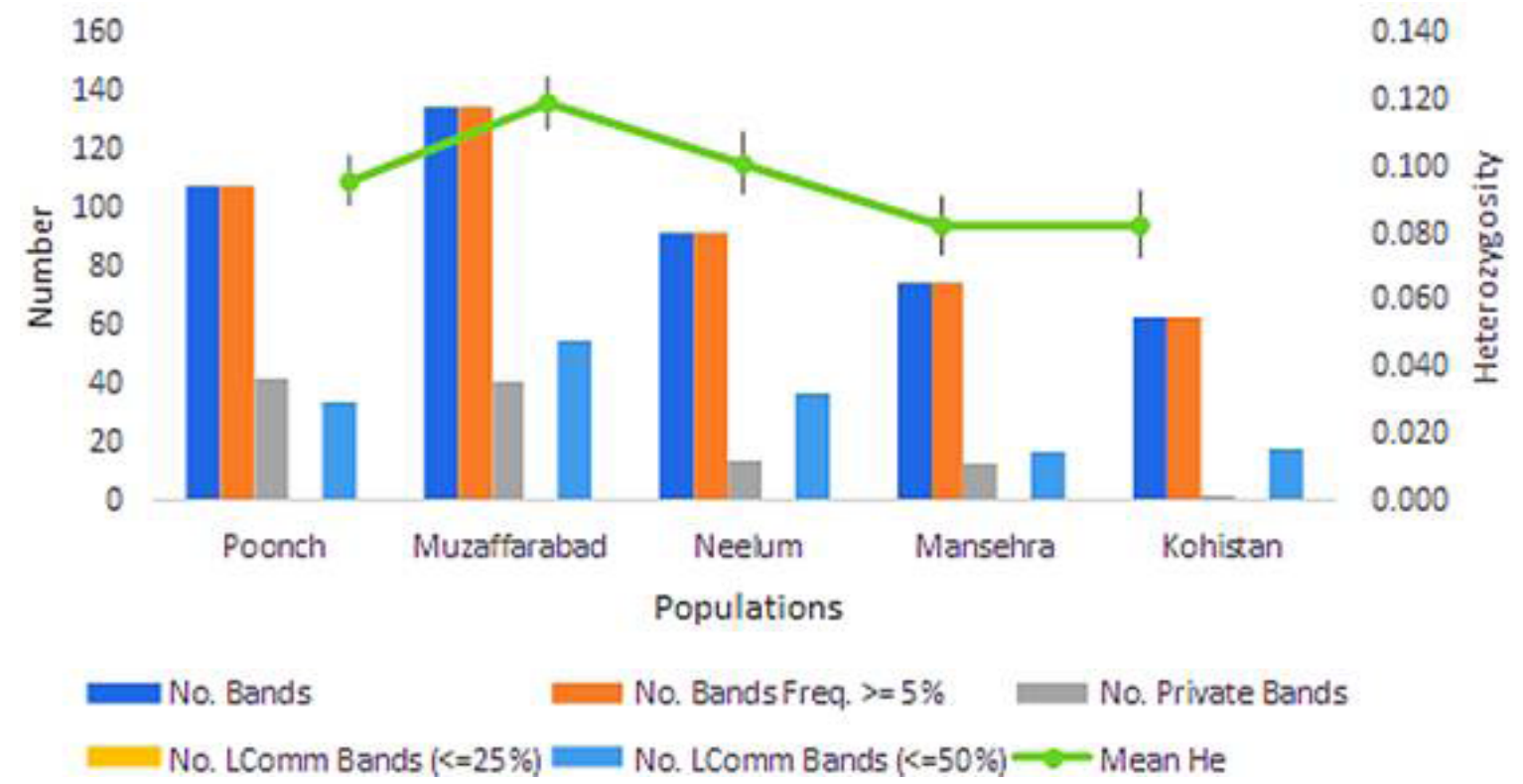

Fig. 3. Total Band Patterns for RAPD markers across different populations of gray langur in Pakistan. No. Bands, number of different bands; No. Private Bands, number of bands unique to a single population; He, expected heterozygosity.

\section{AMOVA and PCOA}

The analysis of molecular variance (AMOVA) was carried out to calculate the $F$-statistics and/or their analogues for estimation of hierarchical partitioning of genetic variation, variance components and their significance level within populations and among populations or regions (Fitzpatrick, 2009). The AMOVA analysis was done using GenAlEx 6.5 software program (Gaudeul et al., 2004). Principal Coordinate Analysis (PCoA) or Classical Multidimensional Scaling was carried out using GenAlEx 6.5. PCoA calculated from geographic distance of different genotypes was calculated based on Global Position System coordinates.

Spatial genetic analysis

To analyze the distribution patterns of genetic variations across different spatial scales, Spatial Genetic Analysis was also done (Diniz-Filho et al., 2013). Global Position System technology was used to collect latitudelongitude coordinates used for regression analyses in conjunction with genetic distances by using Mantel tests (Mantel, 1967) in GenAlEx 6.5 software.

\section{RESULTS}

\section{DNA extraction}

Extraction of DNA was tried from 86 different field samples using standardized methods. However, the successful extractions and amplification was possible for
23 samples with the overall success rate of $24.41 \%$.

Table II.- Discriminatory powers analysis for different RAPD markers used in genetic analysis of gray langurs of Pakistan.

\begin{tabular}{lcccc}
\hline Markers & MI & EMR & RP & PIC \\
\hline OPC-2 & 6.63 & 39.00 & 7.62 & 0.17 \\
OPC-5 & 8.68 & 28.00 & 6.19 & 0.31 \\
OPC-7 & 10.91 & 37.00 & 7.24 & 0.29 \\
OPC-9 & 10.20 & 30.00 & 6.57 & 0.34 \\
OPD-02 & 12.16 & 38.00 & 8.10 & 0.32 \\
OPD-03 & 10.88 & 32.00 & 7.52 & 0.34 \\
OPD-04 & 4.90 & 14.00 & 3.05 & 0.35 \\
OPA-04 & 9.17 & 27.00 & 10.00 & 0.34 \\
Total & 73.54 & 245.00 & 56.29 & 2.46 \\
Mean & 9.19 & 30.63 & 7.04 & 0.31 \\
SE & 2.417 & 2.878 & 0.699 & 0.021 \\
\hline
\end{tabular}

MI, marker index; EMR, effective multiplex ratio; RP, resolving power; PIC, polymorphism information content.

\section{Discriminatory power of markers}

Values of discriminatory power indices of different markers have been presented in Table II. The mean PIC value $( \pm \mathrm{SE})$ was $0.31 \pm 0.02$, which indicated that all markers used were highly polymorphic and efficient. 
The primers with higher RP values are considered more informative in distinguishing the genotypes (Heikrujam et al., 2015).

\section{Allelic diversity}

The highest numbers of total bands and number of different bands with a frequency of $>5 \%$ was recorded in Muzaffarabad population $(n=134)$ and lowest in Kohistan population $(\mathrm{n}=62)$ (Fig. 3).

\section{Observed and effective alleles}

Muzaffarabad population has highest mean numbers of observed alleles $1.077 \pm 0.063$ and effective alleles $1.158 \pm 0.013$ at different loci and Kohistan population has lowest mean numbers of observed alleles $0.511 \pm 0.043$ and effective alleles $1.134 \pm 0.013$ (Table III). On average, the primer OPA-04 revealed the maximum numbers of observed $(0.889 \pm 0.098)$ and effective (1.200) alleles, while OPC-7 exhibited the lowest numbers of observed $(0.638 \pm 0.075)$ and effective alleles $(1.113 \pm 0.008$; Table III).

\section{Polymorphism}

Amplification of RAPD loci exhibited different patterns based on relative frequency (\%) of polymorphism in different gray langur populations (Fig. 4). The highest frequency of polymorphic loci was recorded in Muzaffarabad population (54.29\%) and lowest was recorded in Kohistan population (25.5\%), while the mean polymorphism was $37.71 \pm 5.29(\% \pm \mathrm{SE})$.

Shannon's information and Nei's heterozygosity indices Mean ( \pm SE) values of Shannon's index (I) $0.200 \pm 0.013$ and heterozygosity or Nei's genetic diversity index (He) $0.117 \pm 0.008$ were recorded highest in Muzaffarabad population and lowest in Kohistan population i.e. (I) $0.129 \pm 0.010$ and (He) $0.084 \pm 0.007$, respectively (Table IV). During current study, the mean values of the Shannon's index and Nei's genetic diversity index in all populations was in the ranges of 0.129-0.200 and $0.082-0.117$, respectively (Table IV).

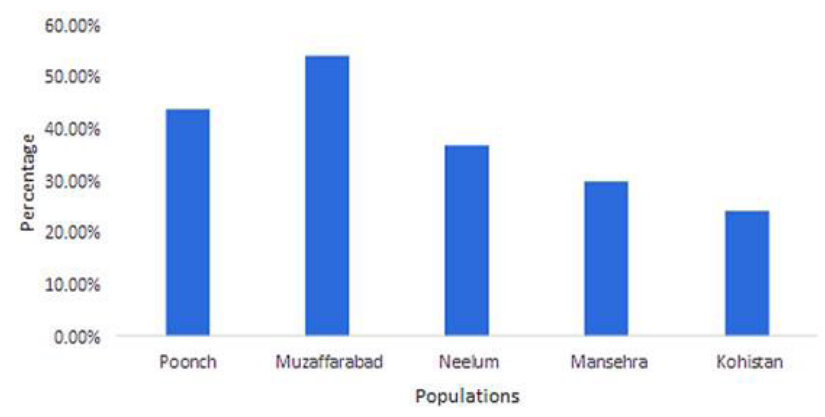

Fig. 4. Frequency of polymorphic loci (\%) in different populations of gray langur in Pakistan.

Table III.- Summary of allelic diversity exhibited by RAPD markers in gray langur populations in Pakistan.

\begin{tabular}{llccccccccccc}
\hline Populations & & OPC-2 & OPC-5 & OPC-7 & OPC-9 & OPD-02 & OPD-03 & OPD-04 & OPA-04 & Mean & SE \\
\hline Poonch & BF & 0.077 & 0.093 & 0.092 & 0.087 & 0.105 & 0.125 & 0.086 & 0.170 & 0.104 & 0.011 \\
& NA & 0.769 & 0.786 & 0.811 & 0.800 & 0.895 & 1.063 & 0.857 & 1.037 & 0.877 & 0.040 \\
& NE & 1.090 & 1.113 & 1.111 & 1.103 & 1.128 & 1.152 & 1.100 & 1.216 & 1.127 & 0.014 \\
Muzaffarabad & BF & 0.144 & 0.114 & 0.086 & 0.147 & 0.126 & 0.150 & 0.100 & 0.207 & 0.134 & 0.013 \\
& NA & 1.231 & 1.071 & 0.757 & 1.267 & 1.158 & 1.125 & 0.857 & 1.148 & 1.077 & 0.063 \\
& NE & 1.174 & 1.136 & 1.105 & 1.179 & 1.152 & 1.183 & 1.121 & 1.214 & 1.158 & 0.013 \\
Neelum & BF & 0.077 & 0.107 & 0.108 & 0.142 & 0.125 & 0.109 & 0.125 & 0.176 & 0.121 & 0.010 \\
& NA & 0.564 & 0.714 & 0.649 & 1.000 & 0.789 & 0.688 & 0.571 & 0.926 & 0.738 & 0.056 \\
& NE & 1.096 & 1.137 & 1.139 & 1.178 & 1.159 & 1.142 & 1.165 & 1.179 & 1.149 & 0.010 \\
Mansehra & BF & 0.103 & 0.107 & 0.074 & 0.100 & 0.066 & 0.078 & 0.071 & 0.194 & 0.099 & 0.015 \\
& NA & 0.769 & 0.714 & 0.595 & 0.600 & 0.421 & 0.500 & 0.429 & 0.704 & 0.591 & 0.047 \\
& NE & 1.127 & 1.137 & 1.090 & 1.131 & 1.085 & 1.101 & 1.094 & 1.204 & 1.121 & 0.014 \\
\multirow{5}{*}{ Kohistan } & BF & 0.077 & 0.143 & 0.090 & 0.056 & 0.105 & 0.115 & 0.190 & 0.173 & 0.119 & 0.017 \\
& NA & 0.410 & 0.607 & 0.378 & 0.333 & 0.526 & 0.563 & 0.643 & 0.630 & 0.511 & 0.043 \\
& NE & 1.101 & 1.141 & 1.124 & 1.071 & 1.140 & 1.153 & 1.160 & 1.185 & 1.134 & 0.013 \\
\hline
\end{tabular}

$\mathrm{BF}$, band frequency; $\mathrm{Na}$, number of alleles; $\mathrm{Ne}$, number of effective alleles. 
Table IV.- Summary of different genetic diversity constants exhibited by RAPD markers in gray langur populations in Pakistan.

\begin{tabular}{llcccccccccc}
\hline Populations & & OPC-2 & OPC-5 & OPC-7 & OPC-9 & OPD-02 & OPD-03 & OPD-04 & OPA-04 & Mean & SE \\
\hline Poonch & I & 0.130 & 0.146 & 0.147 & 0.141 & 0.166 & 0.198 & 0.144 & 0.231 & 0.163 & 0.012 \\
& He & 0.073 & 0.086 & 0.085 & 0.081 & 0.097 & 0.115 & 0.081 & 0.145 & 0.095 & 0.008 \\
Muzaffarabad & I & 0.228 & 0.188 & 0.138 & 0.231 & 0.204 & 0.219 & 0.159 & 0.234 & 0.200 & 0.013 \\
& He & 0.133 & 0.107 & 0.08 & 0.134 & 0.117 & 0.131 & 0.092 & 0.144 & 0.117 & 0.008 \\
Neelum & I & 0.116 & 0.156 & 0.147 & 0.211 & 0.174 & 0.155 & 0.149 & 0.198 & 0.163 & 0.011 \\
& He & 0.070 & 0.096 & 0.092 & 0.128 & 0.108 & 0.097 & 0.098 & 0.123 & 0.102 & 0.006 \\
Mansehra & I & 0.157 & 0.156 & 0.117 & 0.139 & 0.094 & 0.112 & 0.099 & 0.176 & 0.131 & 0.011 \\
\multirow{3}{*}{ Kohistan } & He & 0.094 & 0.096 & 0.069 & 0.088 & 0.058 & 0.069 & 0.063 & 0.117 & 0.082 & 0.007 \\
& I & 0.103 & 0.143 & 0.107 & 0.079 & 0.136 & 0.147 & 0.151 & 0.164 & 0.129 & 0.010 \\
Mean & He & 0.066 & 0.092 & 0.072 & 0.05 & 0.089 & 0.096 & 0.099 & 0.110 & 0.084 & 0.007 \\
& I & 0.147 & 0.158 & 0.131 & 0.160 & 0.155 & 0.166 & 0.140 & 0.201 & 0.157 & 0.007 \\
SE & $\mathrm{He}$ & 0.087 & 0.095 & 0.080 & 0.096 & 0.094 & 0.102 & 0.087 & 0.128 & 0.096 & 0.007 \\
& $\mathrm{I}$ & 0.022 & 0.008 & 0.008 & 0.027 & 0.019 & 0.019 & 0.011 & 0.014 & & \\
\hline
\end{tabular}

I, Shannon's Information Index $=-1 *(p * \operatorname{Ln}(p)+q * \operatorname{Ln}(q))$; He, Expected Heterozygosity $=2 * \mathrm{p} * \mathrm{q}$; where for Diploid Binary data and assuming Hardy-Weinberg Equilibrium, $\mathrm{q}=(1-\text { Band Freq. })^{\wedge} 0.5$ and $\mathrm{p}=1-\mathrm{q}$.

Table V.- Total heterozygosity, genetic diversity, genetic differentiation and gene flow between different populations of gray langur as exhibited by RAPD markers.

\begin{tabular}{lccccccc}
\hline Markers & \multirow{2}{*}{$\begin{array}{c}\text { Total } \\
\text { heterozygosity } \\
\text { (Ht) }\end{array}$} & \multicolumn{2}{c}{$\begin{array}{c}\text { Genetic } \\
\text { diversity }\end{array}$} & & \multicolumn{2}{c}{$\begin{array}{c}\text { Genetic } \\
\text { differentiation }\end{array}$} & $\begin{array}{c}\text { Gene } \\
\text { flow }\end{array}$ \\
& Hs & Dst & & Gst & Rst & (Nm) \\
\hline OPC-2 & 0.096 & 0.087 & 0.009 & & 0.094 & 0.906 & 4.809 \\
OPC-5 & 0.118 & 0.096 & 0.021 & & 0.182 & 0.818 & 2.253 \\
OPC-7 & 0.093 & 0.080 & 0.013 & & 0.145 & 0.855 & 2.958 \\
OPC-9 & 0.106 & 0.096 & 0.010 & 0.095 & 0.905 & 4.748 \\
OPD-02 & 0.106 & 0.094 & 0.012 & & 0.111 & 0.889 & 3.989 \\
OPD-03 & 0.116 & 0.102 & 0.015 & & 0.126 & 0.874 & 3.460 \\
OPD-04 & 0.125 & 0.087 & 0.038 & 0.307 & 0.693 & 1.127 \\
OPA-04 & 0.152 & 0.128 & 0.024 & 0.160 & 0.840 & 2.621 \\
Mean & 0.114 & 0.096 & 0.018 & 0.153 & 0.847 & 3.246 \\
SE & 0.007 & 0.005 & 0.003 & 0.025 & 0.025 & 0.448 \\
\hline
\end{tabular}

Hs, genetic diversity within population; Dst, genetic diversity between population; Gst, genetic differentiation among population; Rst, genetic differentiation within population.

\section{Total heterozygosity or heterogeneity (Ht)}

The mean $( \pm \mathrm{SE})$ value of total heterozygosity or heterogeneity $(\mathrm{Ht})$ as exhibited by different RAPD primers among all populations of gray langurs was $0.144 \pm 0.007$ (Table V). The highest value of $\mathrm{Ht}$ was expressed by the OPA-04 (0.152) followed by OPD-04 (0.125) and OPC-5 (0.118). The lowest value of $\mathrm{Ht}$ was showed by the OPC-7 (0.093).
Genetic diversity within and between populations

The mean value of genetic diversity (Hs) within population as exhibited by all RAPD markers for all populations was $0.096 \pm 0.005$, while the mean genetic diversity between populations (Dst) was calculated as $0.018 \pm 0.003$ (Table V). This indicated very low genetic variations within populations than the variation between different populations.

Gene flow

The mean values $( \pm \mathrm{SE})$ of genetic differentiation constants among populations (Gst) and within populations (Rst) were $0.153 \pm 0.025$ and $0.847 \pm 0.025$. These low values of Gst and higher values of Rst are indicative of a higher gene flow between populations, and thus a lower level of genetic isolation between populations. Therefore, the mean value of gene flow/numbers of migrants $(\mathrm{Nm})$ between populations was higher $(3.246 \pm 0.448)$ ranging between 4.809 (OPC-2) and 1.127 (OPD-04; Table V).

The gene flow $(\mathrm{Nm})$ was significantly correlated with genetic diversity between population (Dst; $r=-0.919$, $\mathrm{p}<0.01$ ), differentiation among populations (Gst; $\mathrm{r}=-0.926$, $\mathrm{p}<0.001$ ) and within populations (Rst; $\mathrm{r}=0.926, \mathrm{p}<0.001$; Table VI). Genetic diversity between population (Dst) was also strongly correlated with genetic differentiation within populations (Rst; $r=-0.968, p<0.0001)$ and among populations (Gst; $r=0.968, p<0.0001$ ). Similarly, and total heterozygosity between population (Ht) was strongly correlated with heterozygosity within population $(\mathrm{Hs}$; $\mathrm{r}=$ $0.856, \mathrm{p}<0.01)$. 
Table VI.- Correlation matrix between total heterozygosity (Ht), genetic diversity within (Hs) and between (Dst) populations, genetic differentiation within (Rst) and between (Gst) populations as exhibited by RAPD markers in gray langur.

\begin{tabular}{lcccccc}
\hline & Ht & Hs & Dst & Gst & Rst & Nm \\
\hline Ht & 1.000 & & & & & \\
Hs & 0.856 & 1.000 & & & & \\
Dst & 0.648 & 0.160 & 1.000 & & & \\
Gst & 0.442 & -0.085 & 0.968 & 1.000 & & \\
Rst & -0.442 & 0.085 & -0.968 & -1.000 & 1.000 & \\
Nm & -0.542 & -0.077 & -0.919 & -0.926 & 0.926 & 1 \\
\hline
\end{tabular}

Table VII.- Pairwise population matrix of Nei genetic identity (above diagonal) and genetic distance (below diagonal) exhibited by RAPD markers in gray langur populations of Pakistan.

\begin{tabular}{lccccc}
\hline Populations & PCH & M/Abad & NLM & MNS & KTN \\
\hline PCH & $* * *$ & 0.984 & 0.981 & 0.982 & 0.973 \\
M/Abad & 0.016 & $* * *$ & 0.983 & 0.980 & 0.971 \\
NLM & 0.019 & 0.018 & $* * *$ & 0.981 & 0.972 \\
MNS & 0.018 & 0.020 & 0.019 & $* * *$ & 0.976 \\
KTN & 0.028 & 0.030 & 0.029 & 0.024 & $* * *$ \\
\hline
\end{tabular}

PCH, Poonch; M/Abad, Muzaffarabad; NLM, Neelum; MNS, Mansehra; KTN, Kohistan.

\section{Genetic similarity and genetic distance}

Nei's genetic similarities and distances were calculated using pairwise population matrix of different populations. As expected, the values of genetic similarities were very high (97-98\%) among populations of gray langurs found in Pakistan/AJK. Inversely, values of genetic distances were very low $(<3 \%)$ between different populations (Table VII). Higher values of genetic similarity and lower values of genetic distance between different populations indicate a higher rate of gene flow and lower heterogeneity (Table V).

Based on genetic distance, dendrogram constructed using UPGMA in Popgene (1.32) divided the whole population of gray langurs into five groups (Fig. 5). Poonch and Muzaffarabad populations very closely related to each other forming a clade, while all others are comparatively distinctly related to each other. Neelum population is out-group of the Muzaffarabad-Poonch clade. Kohistan populations form separate clades. Muzaffarabad and Kohistan populations were the least related (genetic distance 0.030; Table VII).

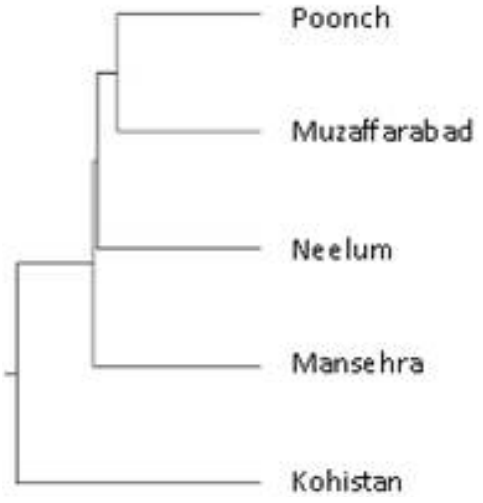

Fig. 5. UPMGA dendrogram based on Nei's genetic distance exhibited by RAPD markers in different populations of gray langurs.

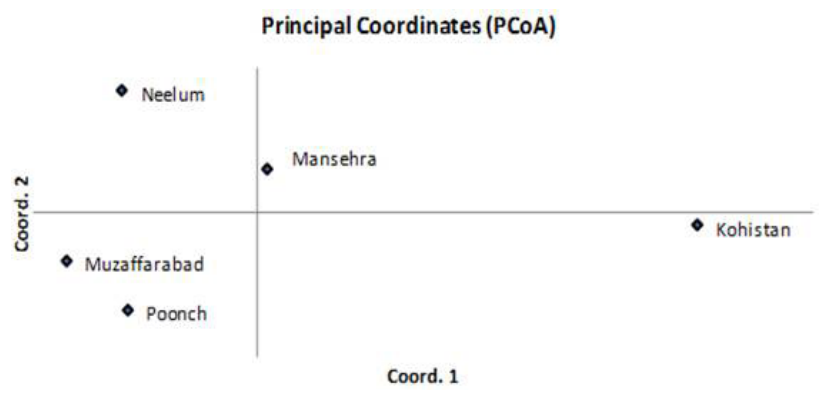

Fig. 6. Graphical presentation of PCoA results for different populations of gray langur.

\section{Multivariate analysis}

Principal coordinate analysis (PCoA) is a spatial way of ordinating the data to visualize the patterns of genetic relationship contained in larger matrices which are impossible to read and interpret. Three-dimensional principal coordinate analysis accounted for 38.99\%, $22.29 \%$ and $21.21 \%$ of the variability as explained by the first three axes with a total $82.50 \%$ variability. Based on the maximum variability among first two axes of the Eigen values, the PCoA output has produced three or four distinct clusters. Two populations of AJK (MuzaffarabadPoonch) form one cluster, while, Neelum, Mansehra and Kohistan populations formed three separate clusters (Fig. 6). PCoA analysis also provided similar clustering pattern as already suggested by dendrograms. PCoA calculated from genetic distance and similarity matrices of genotypes exhibited a lower $(25.56 \%)$ percentage of variability than the different populations $(82.50 \%)$. Based on first two axes of Eigen values, the PCoA results showed different patterns of genotypes (Fig. 7). PCoA calculated from geographic distance of different genotypes obtained by using the global position system coordinates in GenAlEX 
6.5 exhibited a higher $(81.91 \%)$ percentage of variability as also exhibited by the genetic distance $(82.50 \%)$. Based on first two axes of Eigen values, the PCoA results showed three main clusters of genotypes (Fig. 8). These clusters are coinciding with the PCoA results based on genetic distance.

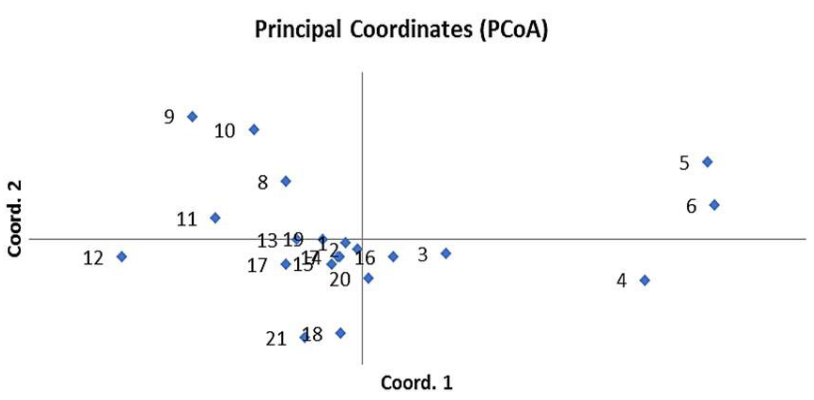

Fig. 7. Graphical presentation of PCoA results for different genotypes of gray langur.

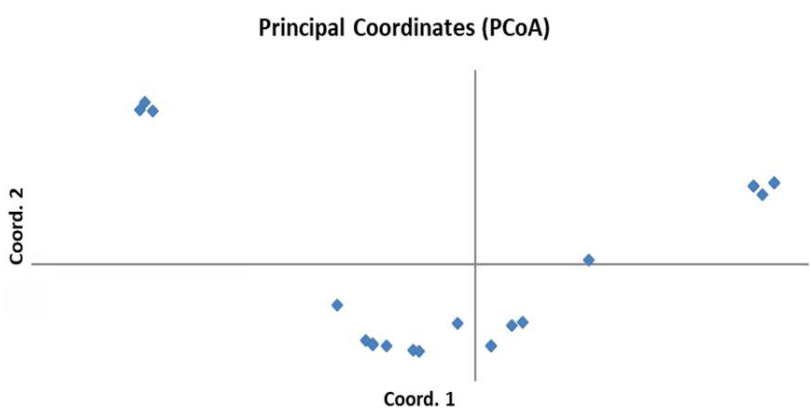

Fig. 8. Graphical presentation of PCoA results based on geographic distance for different genotypes of gray langur.

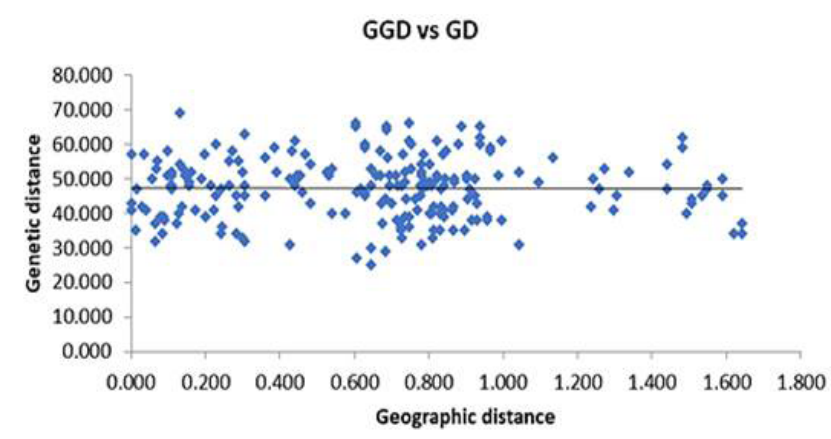

Fig. 9. Association between RAPD based genetic and geographic distances as depicted by Mantel Test.

\section{Spatial genetic analysis}

The calculated value of $R x y=-0.008$, with $\mathrm{P}>0.05$ revealed a nonsignificant relationship between genetic distance and geographic distance (Fig. 9). Hence, the genetic distances between different genotypes are not related to the geographic isolation considerably. Absence of any significant correlation between genetic and geographical distance suggests that geographic distance is not significantly working as effective restricting factor in gene flow between populations as already confirmed by the values of gene flow $(\mathrm{Nm})$.

\section{Analysis of molecular variance (AMOVA)}

Analysis of molecular variance exhibited only $4 \%$ variance between populations and $96 \%$ variance within populations. The Phist $\left(\Phi_{P T}\right)$ value suggested a significance difference in the variance within population and between populations $\left(\Phi_{P T}=0.042 ; \mathrm{p}=0.006\right)$. The results suggested that the variance contributed by individual variation within populations was higher $(96 \%)$ than variation between population $(4 \%)$.

\section{DISCUSSION}

Gray langurs are facing population decline throughout their distribution range including Pakistan (Groves and Molur, 2008; Nag et al., 2011; Minhas et al., 2012). From Himalayan species, $S$. ajax is considered endangered because of its restricted range distribution and continuous population decline (Groves and Molur, 2008). We used RAPD technology to assess the level of genetic isolation in different populations of gray langurs found in Pakistan. We used 8 different RAPD markers for this analysis. The average values of PIC and other parameters of these genetic markers assessment showed that, all genetic markers were highly effective and efficient markers. PIC values range from zero (monomorphic markers) to 0.5 for markers which is present in $50 \%$ of the individuals and absent in others 50\% (Roldàn-Ruiz et al., 2000). The higher values of PIC suggest that, all markers used had the higher levels of efficiency and capability for genetic analysis in the current study. A remarkable difference in the banding patterns, percentages of polymorphic loci and higher PIC values in different langurs' populations indicated a high discriminatory potentials and usefulness of RAPD markers in genetic analysis.

The number and size of fragments/alleles produced correspond to the nucleotide sequence of the primer and DNA template, which is represented in the genome specific fingerprints of RAPD fragments (Welsh et al., 1991). Deferential amplification, as depicted in distinct band sizes, indicated a high genetic variability in different gray langur populations of Pakistan. The average values of observed (na), and effective number of alleles (ne) and percentage of polymorphic loci are considered as indicators of the actual level of genetic variability in the species under question. They high level of polymorphism and unique 
patterns of bands also indicated the highly variability of different gray langur populations found in different areas, as also reported in different earlier studies (Ding et al., 2000; Sanches et al., 2012). The results also indicated that RAPD-PCR technique has potentials of revealing genetic variations among different populations. These techniques have been used in several studies in different vertebrate species including primates (Ding et al., 2000; Rodrigues et al., 2007; Kumar and Gurusubramanian, 2011; Vasave et al., 2014; Shafi et al., 2016; Mudasir et al., 2016).

A relatively larger number of unique bands have been recorded in different populations. The presences of these bands in different populations requires further investigation that, why do they exist? Is their existence a normal phenomenon? Did they arise due to population isolation or inbreeding?, as already highlighted by Schroeder et al. (2009). However, the negative values of inbreeding coefficient (Fis) in all populations suggested that, currently there is no significant inbreeding effect to any population and all populations exhibited heterozygosity excess.

The highest genetic distance was recorded between Muzaffarabad and Kohistan populations. Cluster analysis showed that Poonch and Muzaffarabad populations formed a monophyletic clade, while, all other populations formed almost separate groups. These affinities of populations are acceptable under the current geographic conditions. To detect the distribution patterns of genetic variations across different spatial scales, spatial genetic analysis was also done (Diniz-Filho et al., 2013). RAPD maker showed non-significant relationship between these distance $(R x y=$ $0.008, \mathrm{P}>0.05$ ) suggesting that genetic distance or isolation by distance was not related to the geographic distance (Mantel, 1967).

Higher values of genetic similarity and lower values of genetic distance between different populations indicate a higher rate of gene flow and lower heterogeneity. Seasonal movements of troops and individuals have been recorded in gray langur (Minhas et al., 2012). During these movements, inter-population gene flow possibly occurs. This allows us to propose that physical/ habitat barriers expected for the area are not effective in genetically separating different langur populations, and all gray langur populations of Pakistan and AJK act as a single genetic unit. The present findings about different genetic diversity constants suggest high dissimilarities in genome compositions of different populations of gray langur found in Pakistan and AJK. These values of genetic diversity $(\mathrm{I}=0.129-0.200$ and $\mathrm{He}=0.082-0.117)$ were lower as compared to those suggested by Ding et al. (2000). Using RAPD markers, they calculated the mean values of Shannon's index as 0.55 and 0.85 with the ranges between $0.00-0.162$ and $0.27-1.51$ in white headed langurs and black langurs, respectively. Similar values of genetic diversity indices $(\mathrm{I}=0.13$ and $\mathrm{He}=0.20)$ have been recorded by Shafi et al. (2016) in a RAPD based study on Tor putitora. Rodrigues et al. (2007) calculated the mean values of Nei's diversity index as 0.26 in a RAPD based study on Ozotoceros bezoarticus. Based on the calculated values of the gene diversity indices and as compared with the above studies, it can be assessed that, a moderate level of genetic diversity is present in different langur populations found in Pakistan.

The mean value of gene flow (3.246) between all populations $(>1)$ indicated that, more than one individuals migrate between different population to ensure the genetic flow. The values of $\mathrm{Nm}>1$ suggest a higher level of genetic flow existing between different populations (Mallet et al., 1990). Similar findings have $(\mathrm{Nm}=3.22)$ been reported by Shafi et al. (2016) for Tor putitora using RAPD markers. The finding of the present study also suggests that, the interpopulation migration of individuals still exists. Therefore, the probability of inbreeding and genetic drift is low in these populations, indicating that, the genetic fixation is not a serious problem for the existing langur populations. Slatkin (1987) suggested that values of $\mathrm{Nm}>1$ (i.e., above the minimum number of migrants per generation) needed to avoid differentiation by genetic drift. Population grouping developed by different dendrogram cluster based on genetic distances and similarities seems natural, as expected under the geographic conditions. It appears that despite the presence of possible physical/habitat barriers different geographic populations of gray langur are not completely isolated from one another and gene flow persists between these populations as indicated by the higher values of gene flow exhibited in present study. The lowest similarity between Poonch/Muzaffarabad and Kohistan populations can be expected on distance logic, being located on two extremes of the range Kohistan population is geographically placed at the wider distances from other population, hence, emerged as a separate cluster. However, it is also linked to other population via the adjacent Mansehra population.

\section{CONCLUSIONS}

Concludingly, this study suggested a low level of genetic diversity among different gray langur populations of Pakistan and AJK. Currently, the study did not find any risk of genetic isolation in these sub-populations. However, a higher number of private bands might be the indication that different populations may face the risk of genetic isolation or inbreeding in future. Thus, we suggest that further confirmatory studies should be conducted using other molecular techniques. 
Statement of conflict of interest

Authors have declared no conflict of interest.

\section{REFERENCES}

Abeykoon, A.M.K.W.K., Dhanapala, M.P.C.S., Yapa, R.D. and Sooriyapathirana, S.D.S.S., 2015. An automated system for analyzing agarose and polyacrylamide gel images. Ceylon J. Sci. (Biol. Sci.), 44: 45-54. https://doi.org/10.4038/cjsbs. v44i1.7340

Ahmed, K.B., Awan, M.S. and Anwar, M., 1999. Status of major wildlife species in the Moji Game Reserve, Leepa Valley, Azad Kashmir. Proc. Pak. Congr. Zool., 19: 173-182.

Arif, I.A. and Khan, H.A., 2009. Molecular markers for biodiversity analysis of wildlife animals: A brief review. Anim. Biodivers. Conserv., 32: 9-17.

Arruda, M.P., Costa, W.P., Silva, C.C. and Pimentel, S.M.R., 2012. Development of 22 polymorphic microsatellite loci for the critically endangered Morato's Digger Toad, Proceratophrys moratoi. Int. J. mol. Sci., 13: 12259-12267. https://doi. org/10.3390/ijms 131012259

Bellemain, E., 2004. Genetics of the Scandinavian brown bear (Ursus arctos): Implications for biology and conservation. $\mathrm{PhD}$ thesis, Department of Ecology and Natural Resource Management Agricultural University of Norway, 2004, pp. 38.

Ding, B., Li, H., Zhang, Y., Liu Z. and Wei, Y., 2000. Taxonomic status of the white-headed langur (Trachypithecus francoisi leucoscephalus) using allozyme electrophoresis and random amplified polymorphism DNA (RAPD). Zool. Stud., 39: 313-318.

Diniz-Filho, J.A.F., Soares, T.N., Lima, J.S., Dobrovolski, R., Landeiro, V.L., Telles, M.P.C., Rangel, T.F. and Bini, L.M., 2013. Mantel test in population genetics. Genet. Mol. Biol., 36: 475-485. https:// doi.org/10.1590/S1415-47572013000400002

Fitzpatrick, B.M., 2009. Power and sample size for nested analysis of molecular variance. Mol. Ecol., 18: 3961-3966. https://doi.org/10.1111/j.1365294X.2009.04314.x

Frankham, R., Ballou, J.D. and Briscoe, J.E., 2002. Introduction to conservation genetics. University of Cambridge, Cambridge, UK, pp. 619. https:// doi.org/10.1017/CBO9780511808999

Gaudeul, M., Till-Bottraud, I., Barjon, F. and Manel, S., 2004. Genetic diversity and differentiation in Eryngium alpinum L. (Apiaceae): Comparison of AFLP and microsatellite markers. Heredity, 92: 508-518. https://doi.org/10.1038/sj.hdy.6800443
Groves, C.P. and Molur, S., 2008. Semnopithecus ajax. In: IUCN red list of threatened species, Version 2012.2. Available at: www.iucnredlist.org (accessed on 19 January, 2017).

Hammer, Ø., Harper, D.A.T. and Ryan, P.D., 2001. PAST: Paleontological statistics software package for education and data analysis. Palaeontol. Electron., 4: 9.

Heikrujam, M., Kumar, J. and Agrawal, V., 2015. Genetic diversity analysis among male and female Jojoba genotypes employing gene targeted molecular markers, start codon targeted (SCOT) polymorphism and CAAT box-derived polymorphism (CBDP) markers. Metagene, 5: 9097. https://doi.org/10.1016/j.mgene.2015.06.001

Kayis, S.A., Hakki, E.E. and Pinarkara, E., 2010. Comparison of effectiveness of ISSR and RAPD markers in genetic characterization of seized marijuana (Cannabis sativa L.) in Turkey. Afri. J. agric. Res., 5: 2925-2933.

Kumar, N.S. and Gurusubramanian, G., 2011. Random amplified polymorphic DNA (RAPD) markers and its applications. Sci. Vis., 11: 116-124.

Lacy, R.C., 1997. Importance of genetic variation to the viability of mammalian populations. J. Mammal., 78: 320-335. https://doi.org/10.2307/1382885

Liu, Z.J., Ren, B.P., Hao, Y.L., Zhang, H.R., Wei, F.W. and Li, M., 2008. Identification of 13 human microsatellite markers via cross-species amplification of fecal samples from Rhinopithecus bieti. Int. J. Primatol., 29: 265-272. https://doi. org/10.1007/s10764-007-9175-Z

Mallet, J., Barton, N., Lamas, G., Santisteban, J., Muedas, M. and Eeley, H., 1990. Estimates of selection and gene flow from measures of cline width and linkage disequilibrium in heliconius hybrid zones. Genetics, 124: 921-936.

Mandal, R., Nag, S., Tarafdar, J. and Mitra, S., 2016. A comparison of efficiency parameters of SSR markers and genetic diversity analysis in Amorphophallus paeoniifolius (Dennst.) Nicolson. Brazilian Arch. Biol. Technol., 59: e160492. https:// doi.org/10.1590/1678-4324-2016160439

Mantel, N., 1967. The detection of disease clustering and a generalized regression approach. Cancer Res., 27: 209-220.

Miesfeld, R.L., 1999. Applied molecular genetics. John Wiley and Sons Inc., pp. 312.

Minhas, R.A., Ahmed, K.B., Awan, M.S., Zaman, Q., Dar, N.I. and Ali, H., 2012. Distribution patterns and population status of the Himalayan gray langur (Semnopithecus ajax) in Machiara National Park, Azad Jammu and Kashmir, Pakistan. Pakistan J. 
Zool., 44: 869-877.

Mudasir, H., Sawant, M.S., Pawar, R.A., Pawsae, A.S. and Bhat, F.A., 2016. Stock identification of Nemipterus japonicus along West Coast of India using RAPD markers. SKUAST J. Res., 18: 130137.

Nag, K.S.C., Pramod, P. and Praveen, K., 2011. Taxonomic implications of a field study of morphotypes of hanuman langurs (Semnopithecus entellus) in Peninsular India. Int. J. Primatol., 32: 830-848. https://doi.org/10.1007/s10764-0119504-0

Nassiry, M.R., Javanmard, A. and Tohidi, R., 2009. Application of statistical procedures for analysis of genetic diversity in domestic animal populations. Am. J. Anim. Vet. Sci., 4: 136-141. https://doi. org/10.3844/ajavsp.2009.136.141

Nei, M., 1972. Genetic distance between populations. Am. Nat., 106: 283-292. https://doi.org/10.1086/282771

Nei, M., 1978. Estimation of average heterozygosity and genetic distance from a small number of individuals. Genetics, 89: 583-590.

Nsubuga, A.M., Robbins, M.M., Roeder, A.D., Morin, P.A., Boesch, C. and Vigilant, L., 2004. Factors affecting the amount of genomic DNA extracted from ape faeces and the identification of an improved sample storage method. Mol. Ecol., 13: 2089-2094. https://doi.org/10.1111/j.1365294X.2004.02207.x

Peakall, R. and Smouse, P.E., 2012. GenAlEx 6.5: Genetic analysis in Excel. Population genetic software for teaching and research-an update. Bioinformatics, 28: 2537-2539. https://doi. org/10.1093/bioinformatics/bts460

Pecina-Quintero, V., Anaya-López, J.L., ZamarripaColmenero, A., Montes-García, N., Nuñez-Colín, C., Solis-Bonilla, J.L., Aguilar-Rangel, M.R. and Prom, L., 2012. Genetic diversity of sweet sorghum germplasm in Mexico using AFLP and SSR markers. Pesqui. Agropecuária Bras., 47: 1095-1102. https://doi.org/10.1590/S0100204X2012000800009

Roberts, T.J., 1997. The mammals of Pakistan, revised edition. Oxford University Press, Karachi, pp. 525.

Rodrigues, F.P., Garcia, J.F., Ramos, P.R.R., Bortolozzi, J. and Duarte, J.M.B., 2007. Genetic diversity of two Brazilian populations of the Pampas deer (Ozotoceros bezoarticus, Linnaeus 1758). Braz. J. Biol., 67: 805-811. https://doi.org/10.1590/S151969842007000500002

Roldàn-Ruiz, I., Dendauw, J., Van Bockstaele, E., Depicker, A. and de Loose, M., 2000. AFLP markers reveal high polymorphic rates in ryegrasses (Lolium spp.). Mol. Breed., 6: 125-134. https://doi. org/10.1023/A:1009680614564

Sambrook, J., Fritsch, E.F. and Maniatis, T., 1989. Molecular cloning: A laboratory manual, $2^{\text {nd }}$ ed. Cold Spring Harbor Laboratory Press, New York, pp. 9.14-9.23.

Sanches, A., Galetti Jr, P.M., Galzerani, F., Derazo, J., Cutilak-Bianchi, B. and Hatanaka, T., 2012. Genetic population structure of two migratory freshwater fish species (Brycon orthotaenia and Prochilodus argenteus) from the São Francisco River in Brazil and its significance for conservation. Lat. Am. J. aquat. Res., 40: 177-186. https://doi.org/10.3856/ vol40-issue 1-fulltext-17

Schroeder, K.B., Jakobsson, M., Crawford, M.H., Schurr, T.G., Boca, S.M., Conrad, D.F., Tito, R.Y., Osipova, L.P., Tarskaia, L.A. and Zhadanov, S.I., 2009. Haplotypic background of a private allele at high frequency in the Americas. Mol. Biol. Evol., 26: 995-1016. https://doi.org/10.1093/molbev/ msp024

Shafi, N., Ayub, J., Ashraf, N. and Mian, A., 2016. Genetic diversity in different populations of Mahseer (Tor putitora) in Pakistan: A RAPD based study. Int. J. Agric. Biol., 18: 1181-1187. https:// doi.org/10.17957/IJAB/15.0224

Slatkin, M., 1987. Gene flow and the geographic structure of natural populations. Science, 236: 787792. https://doi.org/10.1126/science. 3576198

Sunnucks, P., 2000. Efficient genetic markers for population biology. Trends Ecol. Evol., 15: 199-203. https://doi.org/10.1016/S0169-5347(00)01825-5

Vasave, S., Saxena, A., Srivastava, S.K. and Barat, A., 2014. Genetic diversity between rainbow trout (Oncorhynchus mykiss, Walbaum) and snow trout (Schizothorax richardsonii, Gray) by RAPD markers. Biol. Chem. Res., 2014: 40-51.

Welsh, J., Honeycutt, R.J., McClelland, M. and Sobral, B.W.S., 1991. Parentage determination in maize hybrids using the arbitrarily primed polymerase chain reaction (AP-PCR). Theor. appl. Genet., 82: 473-476. https://doi.org/10.1007/BF00588601

Yeh, F.C., Yang, R.C. and Boyle, T., 1999. POPGENE version 1.31. Microsoft Windows based freeware for population genetics analysis (http://www.ualberta. ca/_fyeh). University of Alberta and Centre for International Forestry Research, Alberta, Canada.

Zhang, B.W., Li, M., Ma, L.C. and Wei, F.W., 2006. A widely applicable protocol for DNA isolation from fecal samples. Biochem. Genet., 44: 494-503. https://doi.org/10.1007/s10528-006-9050-1 